\title{
RÉGIMEN, DERECHOS FUNDAMENTALES Y SOCIALES EN LATINOAMÉRICA, 2019
}

\author{
Roslem Cáceres López* \\ https://orcid.org/0000-0001-8619-3306 \\ Gaston Jorge Quevedo Pereyra** \\ https://orcid.org/0000-0002-7912-9872
}

RECIBIDO: Julio 2020 / ACEPTADO: Octubre 2020 / PUBLICADO: Enero 2021

\begin{abstract}
Como citar: Cáceres López, Roslem; Quevedo Pereyra, Gaston. (2021). Régimen, derechos fundamentales y sociales en Latinoamérica, 2019. Telos: revista de Estudios Interdisciplinarios en Ciencias Sociales, 23 (1), Venezuela. (Pp.51-66).

DOI: www.doi.org/10.36390/telos231.05
\end{abstract}

\section{RESUMEN}

En la Latinoamérica contemporánea, el significado asimétrico otorgado a las dimensiones de la democracia por los regímenes de cada país, configura la implementación de políticas públicas que se expresan en el amparo o vulneración de los Derechos Fundamentales y Sociales. El objetivo de este trabajo fue realizar una aproximación al estado de los Derechos Fundamentales y Sociales, desde la perspectiva de Dahl (2009) sobre los niveles de democracia identificables en los regímenes latinoamericanos 2017-2019. En esencia, el diseño y aplicación que se socializa es de una metodología de revisión y análisis documental. En ese contexto, el continente latinoamericano transita por una etapa de desarrollo asimétrico de los procesos democráticos observándose polarizaciones, desde Estados con altos niveles de democracia como Uruguay, Costa Rica y Chile, hasta Estados autoritarios como Nicaragua, Venezuela y Cuba. El estudio encontró que las estructuras ideacionales de los regímenes dominantes, configuran teleologías propias de la Presidencia y su entorno, que inciden sobre las dimensiones e indicadores de la democracia, y, en el ejercicio de los derechos Fundamentales y Sociales. Concluye que la modalidad de regímenes configura niveles de democratización que se expresan en el amparo 0 vulneración de Derechos Fundamentales y Sociales. En el caso de los autoritarismos se observa la replicación de estrategias institucionales de minimización en el ejercicio de derechos políticos de hecho, fundamentado en estructuras ideacionales que permean los valores democráticos y tergiversan las dimensiones e indicadores de la democracia.

Palabras clave: Régimen; derechos fundamentales y sociales; niveles de democracia.

\footnotetext{
* Doctora en Derecho. Universidad Privada San Juan Bautista. Universidad Privada del Norte. Correo electrónico: rossinvestigcacelo@gmail.com

** Doctor en Derecho. Universidad Peruana de Ciencias Aplicadas. Correo electrónico: gqinvestigador@gmail.com
} 


\title{
Regime, fundamental and social rights in Latin America, 2019
}

\begin{abstract}
In contemporary Latin America, the asymmetric meaning given to the dimensions of democracy by the regimes of each country, configures the implementation of public policies that are expressed in the protection or violation of Fundamental and Social Rights. The objective of this work was to make an approach to the state of Fundamental and Social Rights, from Dahl's perspective on the levels of democracy identifiable in the Latin American regimes 2017-2019. In essence, the design and application that is socialized is based on a documentary review and analysis methodology. In this context, the Latin American continent goes through a stage of asymmetric development of democratic processes, observing polarizations, from states with high levels of democracy such as Uruguay, Costa Rica and Chile, to authoritarian states such as Nicaragua, Venezuela and Cuba. The study found that the ideational structures of the dominant regimes configure teleologies typical of the Presidency and its environment, which affect the dimensions and indicators of democracy, and, in the exercise of Fundamental and Social rights. It concludes that the modality of regimes configures levels of democratization that are expressed in the protection or violation of Fundamental and Social Rights. In the case of authoritarianism, the replication of institutional strategies of minimization in the exercise of political rights is observed, based on ideational structures that permeate democratic values and distort the dimensions and indicators of democracy.
\end{abstract}

Keywords: Regime; fundamental and social rights; levels of democracy.

\section{Introducción}

Price y Reus-Smith (1998), analizaron las estructuras ideacionales dentro de la teoría constructivista, estableciendo la equidad en la preeminencia de las estructuras materiales y las ideas. En consecuencia, en el ámbito de lo sociopolítico las ideas adquieren trascendencia por cuanto las acciones concomitantes de los sujetos de una sociedad, construyen significados referenciados en la cultura y el contenido discursivo inherente a la sociedad específica (Bevir y Richards, 2009). En Latinoamérica, el significado otorgado a las dimensiones de la democracia por los regímenes de cada país, configura la implementación de políticas públicas que se expresan en el amparo de los derechos individuales y colectivos. Las estructuras ideacionales se imponen, estableciendo teleologías propias que inciden sobre dimensiones e indicadores de la democracia como es el ejercicio de los Derechos Fundamentales y Sociales.

En ese orden, el régimen político corresponde a la expresión del sistema político que articula a una sociedad (Zamorano, 2018), fundamentado en estructuras ideacionales inherentes a la nación y susceptibles de tergiversación por los actores políticos. En Latinoamérica los regímenes políticos históricamente expresan anclajes ideacionales (Hawkins y Rovira, 2017; Mainwaring y Pérez, 2013), donde las constituciones de los Estados como pacto social expresan la legalización del régimen, que no deviene necesariamente en la legitimación de los gobiernos (Sotillo, 2015). Los Estados se encuentran dotados de estructuras que garantizan la trascendencia del orden constituido y el equilibrio en las relaciones de poder entre actores sociales con la preminencia de líderes visibles para las masas quienes encarnan la figura del "protector" promoviendo redes clientelares. El histórico caudillo latinoamericano, desde la 
segunda mitad del siglo XX, se renovó en la figura de Presidentes quienes se apropian de las demandas ciudadanas durante las campañas electorales y posteriormente ejecutan la agenda que responde a la ideología del gobernante. La estructura ideacional se comporta como engranaje que articula al colectivo detrás del paradigma del neocaudillo.

El presidencialismo latinoamericano constituye una extensión de la figura caudillesca decimonónica, aun cuando el Presidente deviene de procesos electorales, institucionalmente se encuentra en la cúspide de la estructura de poder, se desempeña como Jefe del Ejecutivo y máximo representante del Estado en el ámbito internacional (Pasquino, 1983). En ese orden, el sistema presidencial constituye una estructura que concentra poder en una sola persona, quien se encuentra adscrita a uno o varios partidos políticos con quienes establece compromisos, que, se encuentran por sobre los compromisos adquiridos con el electorado (Cortez y Salazar, 2013). Llegado el siglo XXI, en torno la institución presidencial latinoamericana se configuran modalidades de régimen autoritario 0 democrático, que expresan las estructuras ideacionales que fundamentan el régimen (Neto, 2017; Koeneke, 2010).

Los regímenes autoritarios latinoamericanos se caracterizan por la concentración de poder en la figura presidencial (civil o militar), quien discrecionalmente ejerce el gobierno y el flujo de las relaciones de poder al interior de la sociedad. Los programas políticos de los partidos o grupos de poder en torno a la figura presidencial, representan teleologías intemporales en una modalidad de utopía ideacional postergada, mientras en la práctica, el Presidente administra las políticas públicas discrecionalmente y en atención a contenidos que le son propios al paradigma con el que se identifica. El autoritarismo como constructo, admite niveles de pluralismo que legitiman la existencia del régimen, e incluso admiten procesos electorales como procesos formales de afirmación del régimen y perpetuación de la élite dominante, ejerciendo controles sobre el ejercicio de las libertades políticas y la crítica fundamentada (Chacín, 2019).

La oposición es configurada desde el interior del partido gobernante como mecanismo de control de la disidencia y la libertad de expresión es restringida. El discurso de los líderes del régimen autoritario se caracteriza por su ambigüedad y el alto contenido ideológico que convoca las masas a incorporarse a las filas del partido oficial, en torno a principios superiores fundamentados en los referenciales y simbología reconocible por el ciudadano. La normativa jurídica se estructura en función de los objetivos del sector dominante, dotando a las normas de flexibilidad para que se adecuen a las coyunturas que demanden modificaciones legales y responda a los intereses del oficialismo (Chacín, 2019). En estos regímenes la flexibilización normativa atenta contra la tutela judicial y el debido proceso, por cuanto el Estado y sus órganos judiciales se reservan la prerrogativa de restringir las garantías constitucionales en amparo de la integridad del Estado. Los Derechos Fundamentales y sociales son minimizados, argumentando que los intereses colectivos privan sobre los derechos individuales.

En Latinoamérica del siglo XXI se han configurado gobiernos autoritarios de base populista fundamentados en la impostergabilidad de la solución de los conflictos sociales, polarizando a la sociedad entre víctimas y victimarios (Hawkins y Rovira 2017; Laclau, 2006). Las libertades democráticas son restringidas ante la inmanencia del cambio "necesario" y la confrontación del "otro" responsable de los males que aquejan a la sociedad. En la polarización el caudillo personifica la lucha de las victimas contra el opresor, lo que legitima sus acciones y permite la tergiversación del principio de división de poderes (Mudde y Rovira 2017). Los poderes legislativo y judicial se encuentran supeditados al poder ejecutivo, configurando 
estructuras de legitimación de las acciones del poder ejecutivo. Los casos más emblemáticos en la actualidad los constituyen Cuba, Nicaragua y Venezuela.

En otro orden se encuentran los regímenes democráticos latinoamericanos. Corresponde a regímenes fundamentados en la observancia del Pacto Social, donde la toma de decisiones colectivas está normada, concierne a la mayoría de la sociedad y existen suficientes opciones para que los ciudadanos elijan la que consideren pertinente (Bobbio, 1986). Los regímenes democráticos se caracterizan por la división de poderes, el respeto a la diversidad, pluralidad efectiva, toma de decisiones por mayoría, inclusión, alternancia en el ejercicio del poder, sistema electoral transparente, legitimidad de origen de las autoridades, participación y respeto a las minorías. Bajo los regímenes democráticos los Derechos Fundamentales y sociales se encuentran amparados y expresados como principios en las Cartas Magnas (Chacín, 2019). El objetivo de este trabajo fue realizar una aproximación al estado de los Derechos Fundamentales y Sociales, desde la perspectiva de las dimensiones de la democracia identificables en los regímenes latinoamericanos 2017-2019

\section{Derechos Fundamentales}

En principio para efectos de la presente investigación los conceptos de Derechos Humanos y Derechos Fundamentales serán considerados como equivalentes (Aguilar, 2010; Landa, 2006; Fix y Valencia, 1999), aun cuando persiste el debate sobre la distinción entre ambos conceptos (Garrido, 2007; Durán. 2002; Jiménez, 1999). Los Derechos Fundamentales son inherentes a la dignidad humana y su ejercicio puede desempeñarse individual 0 colectivamente. Estos derechos amparan libertades y valores frente a los Estados y todos los poderes públicos (Aguilar, 2016).

Los mencionados valores y libertades emanan del devenir histórico, en el hacer y en el pensar, expresados como acciones culturales de las sociedades. Axiomáticamente los Derechos Fundamentales constituyen una expresión de soberanía popular (Bassa, 2008). Hasta el presente, reconocen cuatro generaciones de Derechos Fundamentales: 1.- Derechos civiles y políticos 2.- Derechos sociales 3. Derechos a la paz, medio ambiente sano y autodeterminación (Gómez, 2003). 4. Derecho al acceso y uso de las nuevas tecnologías de información (Valdés, 2015). Según Pérez (2004) los Derechos Fundamentales definen la esencia del constitucionalismo contemporáneo, por cuanto el pábulo de los Estados Democráticos se encuentra en el amparo de los Derechos Fundamentales y sociales, los cuales requieren de la protección del Estado.

El Estado Democrático de Derecho es una consecuencia del contrato social que legitima la existencia del Estado contemporáneo y ampara a los individuos frente al Estado mediante garantías de protección de los derechos a la vida, a la dignidad, a la expresión, a la identidad, a la privacidad, a la asociación, al ejercicio de derechos políticos, al libre desarrollo de la personalidad, al libre tránsito, a la autodeterminación, a la educación, a la salud, al trabajo, libertad sindical, igualdad ante la Ley, al debido proceso, a la tutela judicial efectiva, a la paz, al medio ambiente sano y el acceso a la información (Bassa et al., 2017).

En la actualidad la esencia del contrato social descasa en las cuatro generaciones de Derechos Fundamentales. No obstante, los alcances de los Derechos Fundamentales difieren en relación a las estructuras ideacionales que fundamentan el Estado y el régimen. En los 
Estados liberales la promoción del individuo posee primacía, mientras que en los Estados sociales de derecho la promoción de la colectividad es lo dominante.

El alcance del amparo a los Derechos Fundamentales es proporcional al Estado de Derecho, en consecuencia, la fragilidad en alguna de las dimensiones del Estado Democrático de Derecho incide sobre la vulnerabilidad de los Derechos Fundamentales.

El amparo de los Derechos Fundamentales por el Estado no se agota en el amparo frente a los poderes públicos, por cuanto actores no estatales potencialmente pueden vulnerar los derechos y el Estado está en la obligación de contener y sancionar a los mencionados actores (Uribe y de Paz, 2015). Las constituciones de los Estados Democráticos de Derecho contemplan, instrumentos de protección de los Derechos Fundamentales y sociales dónde la tutela de los derechos se encuentra expresamente consagrada tanto en lo normativo como en lo procesal.

La supremacía de los Derechos Fundamentales se expresa en el carácter vinculante de la Declaración Universal de los Derechos Humanos (ONU, 1948) y convenciones posteriores, incluso para los Estados cuya constitución no los contempla taxativamente. De acuerdo a la Convención de Viena sobre el Derecho de los Tratados, aplica el 'Pacta sunt servanda', por lo que los Estados están obligados a respetar los Derechos Humanos, considerándolos estructura inherente a sus sistemas normativos y ubicados en la cúspide de la pirámide legislativa (ONU, 1969) .

En ese contexto, los Estados latinoamericanos se encuentran vinculados a la Convención Americana sobre Derechos Humanos y a la Corte Interamericana de Derechos Humanos (CIDH), por lo que en principio, están obligados a cumplir con las decisiones emanadas del CIDH. De lo que se desprende que las fuentes del derecho en materia de Derechos Fundamentales son por principio nacionales e internacionales, aun cuando el debate doctrinario en materia de positivación de los Derechos Fundamentales persista (Aldunate, 2008; Nogueira, 2008; Gómez, 2005; Zavala, 2002). Latinoamérica constituye un continente de vanguardia en materia de ratificación de tratados de Derechos Fundamentales, continentales y universales.

Al año 2020 Argentina, Bolivia, Ecuador y Uruguay eran los únicos países que habían ratificado la totalidad de los 18 tratados en materia de Derechos Fundamentales emanados de convenciones ONU (ONU, 2020).

\section{Gráfico 1. Tratados sobre DDHH ratificados por Estados Latinoamericanos.}

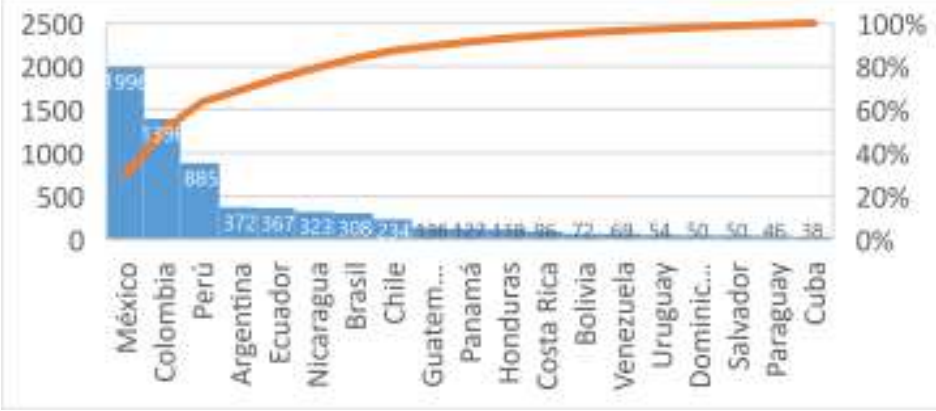

Fuente: ONU (2020) 
No obstante, la ratificación de tratados no deriva en la aplicación de los mismos o la positivación de las normas contenidas en éstos (Anaya, 2017). Para el año 2018 la CIDH, registró un total de 2957 peticiones disgregadas entre los países latinoamericanos en el gráfico 2:

Gráfico 2. Peticiones presentadas antes la CIDH año 2018.

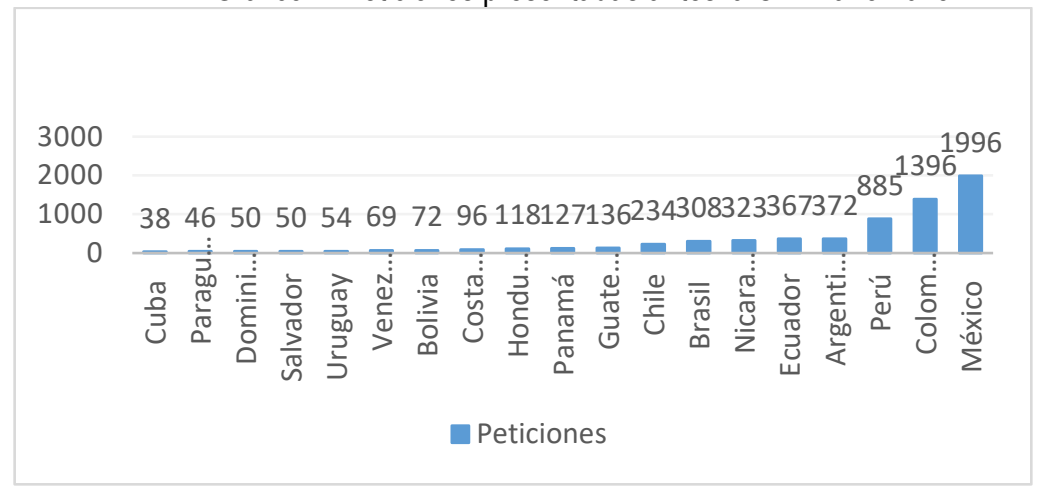

Fuente: CIDH (2019)

La cifra de peticiones ante la $\mathrm{CIDH}$ se ha incrementado anualmente desde las 658 solicitudes del año 2000, hasta los casi tres mil casos registrados en el año 2018. Lo que expresa el incremento en la vulneración de los derechos fundamentales en los países latinoamericanos. En búsqueda de alcanzar el cumplimiento de las convenciones Interamericanas sobre derechos humanos La CIDH adelanta controles de convencionalidad, verificando la incorporación del corpus iuris del $\mathrm{CIDH}$ en el orden jurídico de los Estados ratificantes (CIDH, 2019a; Lovatón, 2017). En ese sentido la CIDH estableció jurisprudencia en elementos materia normativa y procesal:

- El ejercicio del control de convencionalidad de oficio, por los órganos del Poder Judicial: Caso Trabajadores cesados del Congreso vs. Perú" (CIDH, 2006).

- El control de convencionalidad comprende legislación y decisiones judiciales: Caso "Gomes Lund vs. Brasil" (CIDH, 2010).

- El control de convencionalidad comprende decisiones administrativas: Caso López Mendoza contra Venezuela del $1^{\circ}$ de septiembre del 2011 (CIDH, 2011a).

- Reserva la interpretación de la Convención Interamericana de los Derechos Humanos al CIDH: Caso y Atala Riffo y niñas contra Chile. (CIDH, 2012).

- El Control de Convencionalidad puede ser ejercido por cualquier autoridad pública: Caso Gelmán contra Uruguay (CIDH, 2011b).

- El Control de Convencionalidad aplica incluso en normativas refrendadas por comicios.

El control de convencionalidad promovido por la CIDH indujo a que en algunos Estados latinoamericanos se pronunciaran a favor del control de convencionalidad como obligatorio para 
los tribunales nacionales (Castilla, 2014). No obstante, la observancia de las convenciones sobre Derechos Fundamentales, no deviene de su ratificación.

En los Estados latinoamericanos los indicadores evidencian el incremento en la vulneración de derechos fundamentales en la última década (CIDH, 2019a). La acción de los organismos de monitoreo y judiciales internacionales de Derechos Fundamentales, no devienen en acciones coercitivas sobre los infractores por cuanto el signatario de la Convención no se establece relaciones vinculantes con la Corte Interamericana. Las sentencias en la generalidad de los casos están acompañadas de recomendaciones emanadas del organismo con el objetivo de reparar el daño causado, y en casos excepcionales, a instancias de uno varios Estados podrían derivar en acciones políticas y económicas justificadas en base a las sentencias emitidas, más no como acción judicial de los organismos internacionales (Schonsteiner y Couso, 2015).

Esa falta de eficacia en la ejecución de las sentencias emitidas por los organismos internacionales, ha generado cuestionamientos en cuanto a la justificación de la existencia de ésos organismos. Aunado a ello, las diferencias entre las cifras de peticiones (2957) y de las sentencias (126) durante el año 2018 expresa, tanto las limitaciones de la CIDH para atender y procesar las denuncias recibidas y el seguimiento de procesos judiciales contra los infractores (Contesse y Hunneus, 2016). Un simple cálculo evidencia que sólo $4.26 \%$ de los casos alcanzan la emisión de sentencias, que para su aplicación dependen de la voluntad política de los actores estatales y los niveles de democratización en los regímenes imperantes.

\section{Poliarquía y decepción}

Según Dahl (2009), los niveles de democratización de los regímenes pueden establecerse mediante la identificación de la presencia o ausencia de dimensiones específicas: Elección de autoridades, sistema electoral libre y transparente, participación universal de los ciudadanos en el sufragio, libertad de expresión, acceso de todo ciudadano al ejercicio de cargos públicos y acceso a la información, libertad de asociación y el diseño de las políticas públicas estén asociadas a la demanda ciudadana.

Al diagnosticar bajo esas dimensiones a los países latinoamericanos se descubre que, tras el cierre de las dos primeras décadas del siglo XXI, las asimetrías de los regímenes políticos se profundizan y aún con la celebración de elecciones en quince países durante el año 20172019 , los indicadores de Dahl se encuentran ausentes o debilitados en la mayoría de los Estados (Sanahuja, 2019). Democracy Index del 2019 calificó a solo 3 países latinoamericanos con altos niveles de democracia. Como democracias deficientes calificaron 14 países, como regímenes híbridos calificaron 4 países y como autoritarismos se registraron 3 países (Gráfico 3). 
Gráfico 3. Índice de Democracia en Latinoamérica, 2019.

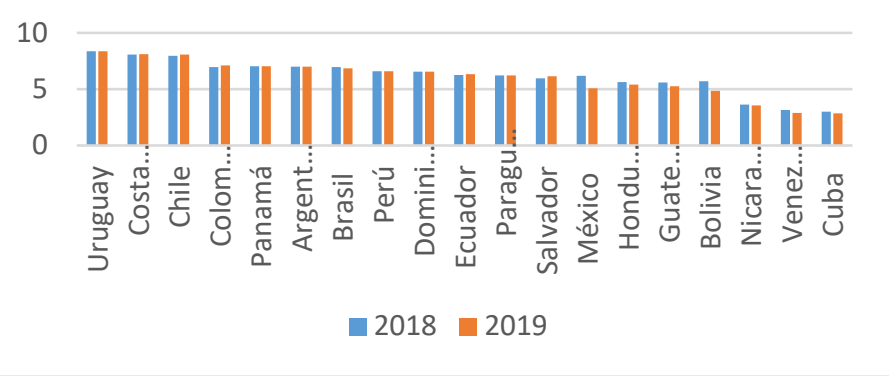

Fuente: The Economist $(2020 ; 2019)$

El índice The Economist (2020), se fundamenta en las mismas categorías señaladas por Dahl (2009), con la singularidad que los engloba en cinco dimensiones: 1. Procesos electorales y pluralismo: Comprende el ejercicio de elección de autoridades y libertad de postulación en los procesos electorales. 2. Funcionamiento del gobierno: Referido a la eficiencia en los procesos y servicios públicos. 3.Participación Política: Incluye derecho al voto, postulación para cargos públicos. 4. Cultura política: Participación en la configuración de políticas públicas. 5. Libertades civiles donde se incluyen libertad de expresión, libertad de información. Además, el Index Democracy comprende 60 indicadores ponderados que coadyuvan en la robustez del índice. Entre los años 2017-2019 los países que mejoraron su índice fueron Chile que se desplazó desde el 7.97 en el año 2018 hasta el 8.08 por lo que ascendió al grupo de países con altos índices de democracia en la región.

El caso chileno fue un caso emblemático, por cuanto las protestas que han sacudieron al país durante los años 2017-2019, no constituyeron un obstáculo para el avance democrático. Según los indicadores en Chile las autoridades abrieron canales de comunicación y concertación con la sociedad civil, mediante vías democráticas. Otro país que logró elevar su índice fue Colombia que se desplazó desde el 6.96 al 7.13. Por otra parte, Brasil, México, Honduras, Guatemala y Bolivia disminuyeron en sus índices. Los casos más destacados de este grupo son México que desciende más de un punto desde los 6.19 al 5.09 y Bolivia que disminuye también un punto de 5.7 al 4.84 . Los tres países clasificados como autoritarios continúan siendo Nicaragua, Venezuela y Cuba con la singularidad que los tres países continúan retrocediendo en el índice de democracia (Eaton, 2017).

Latinoamérica transita por una fuerte crisis de decepción democrática, que se expresa en desconfianza institucional, progresiva pérdida de espacios de participación ciudadana y vulneración de Derechos Fundamentales y Sociales. Los partidos políticos confrontan procesos de fragmentación y dispersión con tendencias ideológicas emergentes, donde se observan coaliciones electorales multifacéticas como el caso de las corrientes evangélicas que progresivamente han alcanzado escaños en los parlamentos latinoamericanos (Malamud y Nuñez, 2019; Pérez y Grundberger, 2018).

La decepción democrática se exteriorizó en la disminución en los niveles de apoyo a la democracia como régimen, desplazándose desde el $52 \%$ en 2017 hasta el $48 \%$ en el año 2018 como promedio regional. El índice de desconfianza en la democracia como forma de 
gobierno alcanzó cifras inéditas, en el caso de México se registró el 10\% de aceptación del régimen democrático (Latinbarómetro, 2018). Según el informe de Latinbarómetro (2018), el incremento en los índices de violencia y desigualdad constituyen factores que inciden en el desencanto e insatisfacción ciudadana.

\section{Autoritarismo y Vulnerabilidad}

La vulnerabilidad democrática de los países latinoamericanos se expresó de forma contundente en el denominado superciclo electoral 2017-2019. La crisis del presidencialismo, ante la incapacidad institucional de brindar respuestas a las demandas sociales, debilita el régimen democrático desplegando Estados paquidérmicos que no encuentran estrategias de optimización de los procesos dentro de la estructura institucional. Las políticas públicas adolecen de ineficiencia desde su confección hasta su implementación derivado de la fragmentación política de los poderes públicos.

La división política en fragmentos de difícil engranaje dentro de coaliciones duraderas, funge de muralla para el avance de iniciativas de ampliación del amparo de los Derechos Fundamentales y sociales, obstaculizadas sistemáticamente por la oposición en los regímenes con democracias imperfectas. En los regímenes autoritarios la hegemonía del partido oficialista exime de responsabilidad, de hecho, a las instituciones y sus funcionarios como es el caso de Cuba, Venezuela y Nicaragua.

En materia de ejercicio de derechos políticos, los procesos electorales latinoamericanos se han desprestigiado progresivamente, como consecuencia de la vulneración de los derechos de participación política, libertad de expresión, libertad de asociación y derecho a la información (Aguilar y Carlin, 2018). Los casos más emblemáticos están asociados a los regímenes autoritarios e híbridos en donde los procesos electorales no constituyen alternativas viables de legitimación (Freidenberg, 2017), por cuanto el descredito de las instituciones electorales derivaron en multitudinarias movilizaciones sociales en países como Nicaragua, Honduras, Venezuela y Bolivia en respuesta a la vulneración de los derechos políticos:

- Nicaragua: El triunfo de Daniel Ortega en las elecciones nicaragüenses del 2006, generó expectativas de equidad social que no cristalizaron por cuanto el renovado Frente Sandinista de Liberación Nacional (FSLN), estableció alianzas con grupos políticos que configuraban una agenda propia de empoderamiento como élite. La estrategia del FSLN , evolucionó en la década siguiente, estableciendo alianzas con el Partido Liberal Constitucional y distintos grupos de empresarios a los que brindó apertura económica, reservando el control del poder al FSLN y la supeditación de los poderes públicos a la presidencia (Cuadra, 2016).

La reelección de Ortega como Presidente de Nicaragua en el año 2016, marcó la consolidación de una modalidad de nepotismo de base electoral. Aun cuando las elecciones presidenciales estuvieron marcadas por el abstencionismo cercano al $70 \%$, el presidente sandinista logró posicionarse en el poder, con el control absoluto del Congreso y afianzado en la apertura económica. No obstante, la ayuda de $\$ 250$ millones al año que recibía de los EEUU fue suspendida desde al año 2017. Durante el año 2018 la violencia generó crisis de gobernabilidad y una violenta represión que registró 351 muertos, como consecuencia de políticas liberales de incremento en la cuota de seguridad social descontada a trabajadores activos y jubilados (ONU,2018). 
La presencia en las calles de grupos paramilitares oficialistas quienes atacaron a los manifestantes, develó una modalidad de represión parapolicial fundamentada en el uso de civiles armados para contrarrestar las manifestaciones. La violenta represión contra las protestas derivó en la degradación del régimen de Nicaragua desde la categoría de híbrido a la categoría de régimen autoritario en el índice de democracia The Economist (2019). La supeditación del Poder Judicial por el Poder Ejecutivo en Nicaragua quedó evidenciada en el informe de Amnistía Internacional (2019) donde se evidencia la penetración del partido oficialista Frente Farabundo Martí de Liberación Nacional dentro del poder judicial y la existencia de una estructura de corrupción que responde a los intereses del oficialismo y sus aliados.

- Honduras: Los gobiernos del Presidente Juan Orlando Hernández desde su primer mandato se caracterizaron por escándalos de corrupción, narcotráfico y apropiación indebida de fondos públicos (Barrachina, 2016); lo que derivó en la caída sustancial de su popularidad de $61 \%$ al $36 \%$ en el año 2017. Las movilizaciones posteriores al proceso electoral del 2017 donde fue declarado reelecto el Presidente bajo acusaciones de fraude, contabilizaron 23 muertos, 1351 detenciones ilegales (Human Rights Watch, 2019a). Las denuncias de fraude abrieron un ciclo de protestas que continuaron en los dos años transcurridos desde las elecciones. El régimen hibrido de Honduras encontró pábulo en la Iglesia, el partido oficialista, las élites económicas afectas al gobierno y el apoyo de EEUU.

No obstante, al año 2019 la reiterada violación de Derechos Fundamentales, las investigaciones de la DEA sobre los vínculos del Presidente con el narcotráfico, el recorte de la ayuda económica de EUU a los países del triángulo norte y la declaración de la Conferencia Episcopal condenado las protestas, debilitaron el gobierno de Hernández, que se mantiene en el poder en un precario nexo con el Partido Nacional y sectores industriales (Breda, 2019). Los derechos fundamentales han sido vulnerados sistemáticamente en Honduras, mediante la represión de las protestas usando armas de fuego, las restricciones de la libertad de expresión y asociación y las innumerables violaciones al debido proceso, en algunos casos denunciadas ante la CIDH. En abril de 2019 la restricción de los derechos sociales a la salud y educación mediante leyes que reforman la legislación en materia de servicios públicos, derivaron en un repunte en las protestas iniciadas en el año 2017.

La criminalización de la crítica al gobierno en mayo del año 2019, restringiendo legislativamente la libertad de expresión y asociación redundó en la extensión de las protestas y el retroceso del gobierno que derogó las medidas de restricción de Derechos Fundamentales y sociales (Amnistia Internacional, 2019). La toma militar de la Universidad Autónoma de Honduras en Tegucigalpa en junio del año 2019 se produjo mediante el ataque con armas de fuego contra los estudiantes que dejó un saldo de tres estudiantes heridos y reavivó las protestas exigiendo la renuncia del Presidente. El régimen hibrido de Honduras ha transitado durante tres años ininterrumpidos de crisis de gobernabilidad y agudizado por la precarización económica de más del $60 \%$ de la población.

- Venezuela: El régimen autoritario avanzó sobre la oposición durante la campaña electoral del año 2018 reprimiendo las concentraciones y encarcelando a dirigentes de oposición. En las barriadas y los pueblos la presencia y el acoso de grupos paramilitares afectos al gobierno denominados "colectivos", impusieron el terror obligando a los ciudadanos a retroceder ante el temor de la desaparición, el encarcelamiento e incluso la muerte. El autoritarismo venezolano tiene sus bases en la tergiversación de los procesos electorales mediante la manipulación de 
las instituciones, la militarización de los poderes públicos y la progresiva limitación de derechos civiles y políticos (Abi, 2018; González y Liendo, 2017).

La concentración de poder en el poder ejecutivo y la supeditación de los poderes públicos a la presidencia. La derrota de la reforma constitucional que perseguía la reelección indefinida del Presidente en el año 2007, el oficialismo se lanzó en campaña durante el año 2008, para convocar ilegalmente un segundo referendo sobre la reelección indefinida de funcionarios con la venia de los poderes legislativo y judicial, argumentando la necesidad de perpetuar el ejercicio del poder por el líder populista Hugo Chávez (Hawkins y Rovira, 2017). El referendo celebrado en 2009 modificó los artículos 160, 162, 174, 192 y 230 de la Constitución aprobando la reelección indefinida de funcionarios.

El proceso electoral del año 2015, renovó las autoridades legislativas brindando una mayoría absoluta a la oposición venezolana. Sin embargo, el legislativo saliente realizó un nombramiento extemporáneo e ilegal de las autoridades del Tribunal Supremo de Justicia, posteriormente el mencionado tribunal inhabilitó a diputados electos y declaró en desacato a la Asamblea Nacional electa en 2015. La concurrencia ante la CIDH no es una alternativa en Venezuela desde el año 2012, como consecuencia de la denuncia realizada por el entonces Presidente Hugo Chávez (Chacín, 2019). En el año 2016, el Tribunal Supremo de Justicia asumió las labores legislativas al extender la habilitación del ejecutivo de emitir leyes, que luego son refrendadas por el Tribunal Supremo de justicia.

Ese proceso de desconocimiento de la voluntad popular marcó el fin de la democracia mínima existente en Venezuela, y, dio paso a un régimen autoritario que se venía construyendo desde el año 2007 (Chacín, 2019). Las movilizaciones populares en contra del gobierno de Nicolás Maduro no han cesado desde el año 2016 y en la misma proporción el gobierno ha violentado sistemáticamente los Derechos Fundamentales y sociales (Human Rights Watch, 2019b).

- Bolivia: En el año 2016 el Presidente boliviano Evo Morales llamó a un referendo popular con el objetivo de lograr su postulación a un cuarto período presidencial. La reforma constitucional fue rechazada y replicando el esquema venezolano, el Presidente Morales interpuso un recurso ante el Tribunal Supremo Electoral, que contraviniendo la soberanía popular aceptó la ilegal postulación de Morales a las elecciones presidenciales 2019. Realizadas las elecciones y ante el anuncio del triunfo de Evo Morales en la primera vuelta se desataron protestas en todo el país que derivaron en la convocatoria a una huelga general. Posteriormente el desconocimiento de sectores del empresariado, sindicatos, policiales, sociedad civil, la Central Obrera Boliviana (COB) aunado al desconocimiento de las elecciones por EEUU, Brasil y Colombia profundizaron la crisis de gobernabilidad en Bolivia. El posterior informe de la Organización de Estados Americanos, donde se identificaron irregularidades en el proceso de elecciones y la solicitud de renuncia por parte de las Fuerzas Armadas bolivianas, derivaron en la renuncia del Presidente (Human Rights Watch, 2018)..

Obsérvese que en los cuatro casos citados la vulneración de los Derechos Fundamentales y Sociales son una constante. En los casos de Venezuela Nicaragua y Honduras la supeditación de los poderes públicos al Poder Ejecutivo y su estructura ideacional, desdibujó el principio de separación de poderes, de donde se desprendieron violaciones subsecuentes a los derechos de elección libre y trasparente de autoridades, asociación y postulación a cargos públicos (ONU, 2019). Aunado a ello, la represión contra la oposición política vulnera sistemáticamente los 
derechos de libre tránsito, libertad de expresión, y debido proceso. Como resultado, los derechos Fundamentales y Sociales de la mayoría de los países latinoamericanos evidencian deterioros progresivos asociados al desplazamiento hacia regímenes autoritarios fundamentados en estructuras ideacionales de vocación centralizadora y personalista en el ejercicio del poder.

\section{Conclusión}

El estudio encontró que las estructuras ideacionales de los regímenes dominantes, configuran teleologías propias de la Presidencia y su entorno, que inciden sobre dimensiones e indicadores de la democracia y en el ejercicio de Derechos Fundamentales y Sociales. En ese contexto, el continente latinoamericano transita por una etapa de desarrollo asimétrico de los procesos democráticos observándose polarizaciones, desde Estados con altos niveles de democracia como Uruguay, Costa Rica y Chile, hasta Estados autoritarios como Nicaragua, Venezuela y Cuba.

La modalidad de regímenes configura niveles de democratización observables en el amparo o vulneración de Derechos Fundamentales y Sociales. En el caso de los autoritarismos se observa la replicación de estrategias institucionales de minimización en el ejercicio de derechos políticos de hecho, fundamentado en estructuras ideacionales que permean los valores democráticos y tergiversan las dimensiones e indicadores de la democracia.

Los controles de convencionalidad del $\mathrm{CIDH}$, no han logrado detener el deterioro de las estructuras ideacionales de contenido democrático que impulsaron la oleada de democratización de finales del siglo XX en Latinoamérica. Por el contrario, la emergencia de gobiernos personalistas en regímenes presidenciales neocaudillistas, debilitan los valores democráticos y registran un exponencial crecimiento en la vulneración de Derechos Fundamentales y Sociales.

\section{Referencias Bibliográficas}

Abi, Sahar. (2018). Populism in Venezuela: The role of the opposition. En Hawkins, Kirk; Carlin, Ryan; Littvay, Levente; Rovira, Cristóbal. The Ideational Approach to Populism: Concept, Theory, and Analysis. Routledge. Reino Unido.

Aguilar Cavallo, Gonzalo. (2010). Derechos fundamentales-derechos humanos. ¿Una distinción válida en el siglo XXI?. Boletín mexicano de derecho comparado, 43(127), Chile. (Pp. 15-71).

Aguilar Cavallo, Gonzalo. (2016). Principios de interpretación de los derechos fundamentales a la luz de la jurisprudencia chilena e internacional. Boletín mexicano de derecho comparado, 49(146), Chile.

(Pp. 13-59). http://dx.doi.org/10.22201/iii.24484873e.2016.146.10505

Aguilar, Rosario; Carlin, Ryan. (2018). Populist Voters: The role of the voter authoritarianism and ideology. En Hawkins, Kirk; Carlin, Ryan; Littvay, Levente; Rovira, Cristóbal. The Ideational Approach to Populism: Concept, Theory, and Analysis. Routledge. Reino Unido.

Aldunate, Eduardo. (2008). Derechos fundamentales. Legal Publishing. Chile.

Amnistía Internacional. (2019). Informe Anual 2019. Extraído de https://www.amnesty.org/download/Documents/AMR0113532020SPANISH.PDF 
Anaya Muñoz, Alejandro. (2017). Los regímenes internacionales de derechos humanos: la brecha entre compromiso y cumplimiento. Revista IUS, 11(40), México. (Pp. 159-181). https://doi.org/10.35487/rius.v11i40.2017.341

Barrachina Lison, Carlos. (2016). Democracia, política y violencia en Honduras (20062014). Península, 11(1), Honduras. 25-64). https://dx.doi.org/10.1016/i.pnsla.2016.01.002

Bassa Mercado, Jaime. (2008). Notas para una teoría democrática del poder constituyente. Nomos, (1), Chile. (Pp. 41-70).

Bassa Mercado, Jaime; Ferrada Borquez, Juan Carlos; Viera Álvarez, Christian. (2017). La interpretación institucional de los derechos fundamentales en un Estado democrático de derecho. Cuestiones constitucionales, (37), Chile. (Pp. 265-291). https://dx.doi.org/10.22201/iii.24484881e.2017.37.11459

Bevir, Mark; Richards, David. (2009). Decentring policy networks: a theoretical agenda. Public Administration, 87(1), Estados Unidos. (Pp. 3-14). https://dx.doi.org/10.1111/j.14679299.2008.01736.x

Bobbio, Norberto. (1986). El futuro de la democracia. Fondo de Cultura Económica. México.

Breda, Tiziano. (2019). La represión fomenta la inestabilidad en Honduras mientras la protesta continúa. Extraído de https://www.crisisgroup.org/es/latin-america-caribbean/centralamerica/honduras/crackdown-raises-stakes-honduran-protesters-march

Castilla Juárez, Karlos. (2014). Control de convencionalidad interamericano: una mera aplicación del derecho internacional. Derecho del Estado, (33), México. (Pp. 149-172). Extraido de: https://bit.ly/307T89H

Chacín Fuenmayor, Ronald. (2019). El nuevo autoritarismo latinoamericano: Un reto para la democracia y los derechos humanos (análisis del caso venezolano). Estudios constitucionales, 17(1), Venezuela. (Pp. 15-52). https://dx.doi.org/10.4067/S0718$\underline{52002019000100015}$

$\mathrm{CIDH}$. (2006). Caso trabajadores cesados del Congreso (Aguado Alfaro y otros) vs. Perú. Sentencia de 24 de noviembre de 2006 . Extraído de http://www.corteidh.or.cr/docs/casos/articulos/seriec_158_esp.pdf

$\mathrm{CIDH}$. (2010). Caso Gomes Lund y otros (Guerrilha do Araguaia) vs. Brasil. Sentencia de 24 de noviembre de 2010.

http://fueromilitar.scin.gob.mx/Resoluciones/seriec_219_esp.pdf

CIDH. (2011a). López Mendoza contra Venezuela. Sentencia del $1^{0}$ de septiembre del 2011. Extraído

https://www.corteidh.or.cr/CF/jurisprudencia2/ficha tecnica.cfm?nld Ficha=354

$\mathrm{CIDH}$. (2011b). Caso Gelmán contra Uruguay. Sentencia del 24 de febrero del 2011. Extraído de http://www.corteidh.or.cr/docs/casos/articulos/seriec_221_esp1.pdf

CIDH. (2012). Caso y Atala Riffo y niñas contra Chile. Sentencia del 24 de febrero del 2012. Extraído de http://www.corteidh.or.cr/docs/casos/articulos/seriec_239_esp.pdf

CIDH. (2019a). Control de Convencionalidad. Cuadernillo de Jurisprudencia de la Corte Interamericana de los Derechos Humanos. № 7 Extraído de https://archivos.juridicas.unam.mx/www/bjv/libros/10/4566/9.pdf

CIDH. (2019b). Peticiones Pendientes de Estudio Inicial. p 4. Extraído de http://www.oas.org/es/cidh/multimedia/estadisticas/estadisticas.html 
Contesse, Jorge; Huneeus, Alexandra. (2016). Introduction to the Symposium on the American Convention on Human Rights and its New Interlocutors. American Journal of International Law, (113), Estados Unidos. (Pp. 351-354). https://doi.org/10.1017/aju.2019.66

Cortez Salinas, Josafat; Salazar Rebolledo, Grisel. (2013). Democracia presidencial 0 parlamentaria: ¿qué diferencia implica?" Explorando las influencias institucionalistas en el análisis de Juan Linz. Cuestiones constitucionales, (29), México. (Рp. 83-107). https://doi.org/10.1016/S1405-9193(13)71291-5

Cuadra Lira, Elvira. (2016). Las elites y los campos de disputa en Nicaragua: Una mirada retrospectiva. Península, 11(1), Nicaragua. (Pp. 85-101). https://dx.doi.org/10.1016/j.pnsla.2016.01.004

Dahl, Robert. (2009). Poliarquía. Tecnos. España.

Durán Rivera, Willman. (2002). La protección de los derechos fundamentales en la doctrina y jurisprudencia constitucional. Ius et Praxis, 8(2), Bolivia. (Pp. 177-194). http://dx.doi.org/10.4067/S0718-00122002000200006

Eaton, Kent. (2017). Policy Regime Juxtaposition in Latin America. Colombia Internacional, (90), Estados Unidos. (Pp. 37-65). https://dx.doi.org/10.7440/colombiaint90.2017.02

Fix, Héctor; Valencia, Salvador. (1999). Derecho constitucional mexicano y comparado. Porrúa. México.

Freidenberg, Flavia. (2017). ¿Qué es una Buena Elección?: El Uso de los Informes de las Misiones de Observación Electoral para Evaluar los Procesos Electorales Latinoamericanos (2013-2016). Dados, 60(4), México.

(Pp.

1095-1142). https://doi.org/10.1590/001152582017143

Garrido, María. (2007). Derechos fundamentales y estado social y democrático de derecho. Diles. España.

Gómez, Gastón. (2005). Derechos fundamentales y recurso de protección. Ediciones Universidad Diego Portales. Chile.

Gómez, Yolanda. (2003). Derechos y libertades. Sanz y Torres. España.

González, Manuel; Liendo, Nicolás. (2017). La defensa colectiva de la democracia en América Latina: ¿Por qué? ¿Cómo? ¿Cuándo?. Análisis Político, 30(91), Colombia. (Pp.3-17). https://dx.doi.org/10.15446/anpol.v31n91.70261

Hawkins, Kirk; Rovira, Cristóbal. (2017). The Ideational Approach to Populism. Latin American Research Review, 52(4), Estados Unidos. (Pp. 513-528). http://doi.org/10.25222/larr.85

Human Rights Watch. (2018). Bolivia Eventos 2018. Extraído de https://www.hrw.org/worldreport/2018/country-chapters/bolivia

Human Rights Watch. (2019a). Honduras Eventos 2018. Extraído de https://www.hrw.org/es/world-report/2019/country-chapters/326040

Human Rights Watch. (2019b). Venezuela Eventos 2018. Extraído de https://www.hrw.org/worldreport/2019/country-chapters/venezuela

Jiménez, Javier. (1999). Derechos fundamentales: concepto y garantías, Trotta. España. Koeneke, Herbert. (2010). Transiciones políticas y libertades ciudadanas: Algunas consideraciones sobre América Latina a partir de los años 70. Argos, 27(53), Perú. (Pp. 123-144).

Laclau, Emesto. (2006). La deriva populista y la centroizquierda latinoamericana. Nueva sociedad, (205), Venezuela. (Pp. 56-61). 
Landa, César. (2006). Constitución y fuentes del derecho. Palestra. Perú.

Latinbarómetro. (2018). Latino barómetro: Opinión Pública Latinoamericana. Extraído de http://www.latinobarometro.org/latContents.jsp

Lovatón Palacios, David. (2017). Control de convencionalidad interamericano en sede nacional: una noción aún en construcción. Revista Direito e Práxis, 8(2), Perú. (Pp.1389-1418). https://doi.org/10.12957/dep.2017.27730

Mainwaring, Scott; Pérez, Aníbal. (2013). Democracies and Dictatorships in Latin America:

Emergence, Survival, and Fall. Cambridge University Press. Reino Unido.

Malamud, Carlos; y Nuñez, Rogelio. (2019). Tiempos recios y final de época en América Latina: un balance del ciclo electoral 2017-2019. Análisis del Real Instituto Elcano, (119), España. (Pp. 1-11).

Mudde, Cas; Rovira, Cristóbal. (2019). Populismo. Una introducción muy corta. Alianza editorial. España.

Neto Terto, Ulisses. (2017). Democracy, social authoritarianism, and the human rights state theory: towards effective citizenship in Brazil. The International Journal of Human Rights,

21(3), Brasil. (Pp. 289-305). https://doi.org/10.1080/13642987.2017.1298733

Nogueira, Humberto. (2008). Derechos fundamentales y garantías constitucionales. Librotecnia. Chile.

ONU. (1948). LA Declaración Universal de los Derechos Humanos. Extraído de https://www.un.org/es/universal-declaration-human-rights/

ONU. (1969). Convención de Viena sobre el Derecho de los Tratados. Extraído de http://www.oas.org/36ag/espanol/doc referencia/convencion viena.pdf

ONU. (2018) Human rights violations and abuses in the context of protests in Nicaragua 18 April - 18 August 2018. Oficina del Alto Comisionado de las Naciones Unidas para los Derechos Humanos. Extraído

https://www.ohchr.org/Documents/Countries/Nl/HumanRightsViolationsNicaraguaApr_Aug 2018 EN.pdf

ONU. (2019). Human Rights report on Venezuela urges immediate measures to halt and remedy grave rights violations. Oficina del Alto Comisionado de las Naciones Unidas para los Derechos Humanos. Extraído

https://www.ohchr.org/en/NewsEvents/Pages/DisplayNews.aspx?NewsID=24788\&LangID $=\mathrm{E}$

ONU. (2020). Status of Ratifications: Interactive Dashboard. Oficina del Alto Comisionado de las

Naciones Unidas para los Derechos Humanos. Extraído de https://indicators.ohchr.org/

Pasquino, Gianfranco. (1983). Formas de gobierno: En Bobbio, Norberto; Matteucci, Nicola;

Pasquino, Gianfranco. Diccionario de política. Siglo XXI Editores. México.

Pérez, Antonio. (2004). Los derechos fundamentales. Tecnos. España.

Pérez, José; Grundberger, Sebastian. (2018). Evangélicos y Poder en América Latina. Konrad Adenauer Stiftung (KAS). Perú.

Price, Richard; Reus-Smit, Christian. (1998). Dangerous Liaisons? Critical International Theory and Constructivism. European Journal of International Relations, 4(3), Estados Unidos. (Pp. 259- 294). https://doi.org/10.1177/1354066198004003001 
Sanahuja, José. (2019) América Latina: malestar democrático y retos de la crisis de la globalización. En Instituto Español de Estudios Estratégicos. Panorama Estratégico Mundial. Ministerio de Defensa, Secretaría General Técnica. España.

Schonsteiner, Judith; Couso, Javier. (2015). La implementación de las decisiones de los órganos del sistema interamericano de derechos humanos en Chila: Ensayo de un balance. Revista de derecho Coquimbo, 22(2), Chile. (Pp. 315-355). https://dx.doi.org/10.4067/S071897532015000200011

Sotillo Antezana, Aquiles. (2015). La nueva clasificación de los derechos fundamentales en el nuevo constitucionalismo latinoamericano. Ciencia y Cultura, (35), Bolivia. (Pp. 163-183).

The Economist Intelligence Unit. (2019). Democracy Index 2018. EIU. Reino Unido. Extraído de https://datawrapper.dwcdn.net/jkMCN/2/?abcnewsembedheight=550

The Economist Intelligence Unit. (2020). Democracy Index 2019. EIU. Reino Unido. Extraído de http://www.eiu.com/democracy-2019

Uribe Arzate, Enrique; de Paz González, Isaac. (2015). Los efectos de los derechos fundamentales en el tiempo. Boletín Mexicano de Derecho Comparado, 1(144), México. (Pp. 1155-1196). https://dx.doi.org/10.22201/iij.24484873e.2015.144.4963

Valdés, Erick. (2015). Bioderecho, daño genético y derechos humanos de cuarta generación. Boletín Mexicano de Derecho Comparado, 48(144), Chile. (Pp. 1197-1228). http://dx.doi.org/10.22201/iii.24484873e.2015.144.4964

Zamorano Farías, Raúl. (2018). Sistemas de gobierno en América Latina. El caso chileno. Cuestiones constitucionales, (38), Chile. (Pp. 3-31). https://dx.doi.org/10.22201/iii.24484881e.2018.38.11873

Zavala, Jorge. (2002). Derecho constitucional. Edino. Ecuador. 